to confirm observations from DE019. Pts were subgrouped by CRP level at entry (CRP $<1 \mathrm{mg} / \mathrm{dL}, \geq 1 \mathrm{mg} / \mathrm{dL}$ ). Baseline (BL) demographics and disease characteristics were summarized for each group. Clinical efficacy was assessed through swollen/tender joint count (S/TJC) at 66/68 joints, pain, patient global assessment (PtGA), physician global assessment (PhGA), CRP, clinical disease activity index (CDAl), 28-joint disease activity score based on CRP (DAS28CRP), and proportions of pts achieving ACR20/50/70. Functional outcomes were assessed by the disability index of the health assessment questionnaire (HAQ-DI), and radiographic outcomes by the modified total Sharp score (mTSS). Outcomes were assessed in pts with CRP $<0.8 \mathrm{mg} / \mathrm{dL}$ in DE019, which included pts with CRP levels as low as $0.75 \mathrm{mg} / \mathrm{dL}$ Observed data are reported at week 24 . Results: In DE019, 183 pts (89 and 94 in the ADA and PBO arms, respectively) had CRP $<1 \mathrm{mg} / \mathrm{dL}$ and 224 pts (118 and 106, respectively) had CRP $\geq 1 \mathrm{mg} / \mathrm{dL}$. Pts with elevated CRP had higher BL disease activity compared with those with CRP $<1 \mathrm{mg} / \mathrm{dL}$ at entry (not shown). After 24 wks of treatment with ADA, pts in both CRP subgroups experienced significant improvements in most clinical and functional outcomes vs PBO (Table). In pts with CRP $<0.8 \mathrm{mg} / \mathrm{dL}$, the ACR20 response rate difference $(30.4, \mathrm{p}<.001)$ and the difference in $\triangle$ mTSS $(-1.3$, $p<.05)$ for ADA vs PBO treatment were still significant. Compared to pts with CRP $<1 \mathrm{mg} / \mathrm{dL}$, pts with elevated CRP experienced greater clinical and functional improvements. However, within the ADA subgroups, pts with elevated CRP had smaller differences vs PBO in mTSS, perhaps reflecting higher joint damage at BL. In general, similar trends were observed in MUSICA (not shown).

\begin{tabular}{|c|c|c|c|c|c|c|}
\hline & \multicolumn{3}{|c|}{$C R P<1$} & \multicolumn{3}{|c|}{$C R P \geq 1$} \\
\hline & $\begin{array}{l}\text { PBO } \\
n=79\end{array}$ & $\begin{array}{l}\text { ADA } \\
n=74\end{array}$ & Difference & $\mid \begin{array}{l}\text { PBO } \\
n=75\end{array}$ & $\begin{array}{l}\text { ADA } \\
n=101\end{array}$ & Difference \\
\hline TJC68 & -13.2 & -17.2 & -3.2 & -11.7 & $-16.5^{\mathrm{e}}$ & $-6.0 * * * *$ \\
\hline SJC66 & -7.1 & -11.3 & $-4.3^{* *}$ & $\mid-6.7$ & $-12.5^{\circ}$ & $-5.0^{* * * *}$ \\
\hline Pain & -13.0 & -24.5 & $-11.7^{* * * *}$ & $-20.3^{c}$ & -35.8 & $-14.4^{* * * *}$ \\
\hline PtGA & -11.0 & -24.2 & $-13.2^{* * * *}$ & $\mid-20.7^{6}$ & -35.5 & $-16.1^{* * * *}$ \\
\hline PhGA & -24.4 & -35.0 & $-10.2^{* *}$ & $-28.0^{6}$ & -43.2 & $-14.2^{* * *}$ \\
\hline HAQ-DI & $-0.26^{\prime}$ & -0.49 & $-0.24 * *$ & $\mid-0.38$ & -0.68 & $-0.31 * * *$ \\
\hline CRP & 0.1 & 0.02 & $-0.08^{\star}$ & -0.54 & -2.05 & -1.0 \\
\hline DAS28- & -1.19 & -1.92 & $-0.75^{* * *}$ & $\mid-1.26^{c}$ & $-2.33^{\circ}$ & $-1.10^{* * * *}$ \\
\hline CDAI & -15.9 & -22.7 & $-7.6^{* * * *}$ & $-15.7^{c}$ & $-26.5^{\circ}$ & $-11.1^{* * * *}$ \\
\hline$A C$ & $32 / 79$ & $50 / 74$ & & | $30 / 7$ & $82 / 99$ & $41^{* * * *}$ \\
\hline ACR50, & $9 / 79(1$ & $34 / 74$ & $35^{* * * *}$ & $11 / 7$ & $46 / 99(46)$ & $31^{* *}$ \\
\hline ACR70, niN (\%) & $6 / 79(8)$ & $19 / 74(26)$ & $18^{* * *}$ & $0 / 72(0)$ & $19 / 99(19)$ & $19 * * *$ \\
\hline mTSS & $0.93^{\mathrm{a}}$ & $-0.32^{\mathrm{b}}$ & $-1.30^{* * *}$ & $1.63^{\mathrm{g}}$ & $0.79^{\circ}$ & -0.84 \\
\hline \multicolumn{7}{|c|}{ 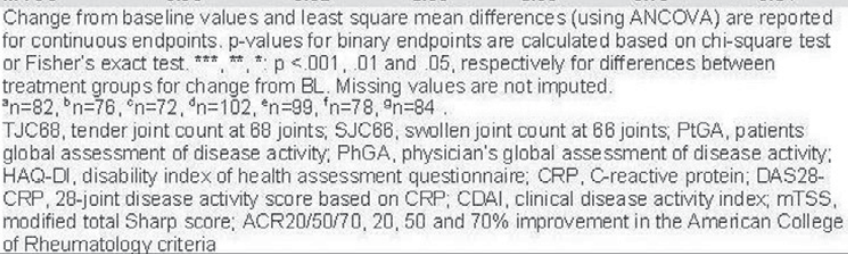 } \\
\hline
\end{tabular}

Conclusions: While pts with elevated CRP at entry experienced larger improvements from $\mathrm{BL}$ in clinical and functional outcomes upon treatment, significant improvements in most outcomes were also observed in those without elevated CRP at entry (as low as $0.75 \mathrm{mg} / \mathrm{dL}$ ), suggesting that an elevated CRP may not be required to see differences between active and inactive treatment. References:

[1] Von Vollenhoven et al. 2015, Arthritis Rheum 67: 2855-2860.

[2] Keystone et al. 2004. Arthritis Rheum;5:1400-11.

[3] Kaeley et al. 2016. J Rheum;8:1480-9.

Acknowledgements: AbbVie: study sponsor, contributed to study design, data collection, analysis and interpretation; writing, reviewing, and approval of the final version. Medical writing assistance: Naina Barretto, of AbbVie.

Disclosure of Interest: C. Scoville Speakers bureau: AbbVie, J. Suboticki Employee of: AbbVie, S. Zhong Employee of: AbbVie, E. Keystone Grant/research support from: AbbVie, Amgen, AstraZeneca, Biotest, Bristol-Myers Squibb, Centocor, F Hoffmann-LaRoche, Genentech, Genzyme, Merck, Novartis, Nycomed, Pfizer, and UCB., Consultant for: AbbVie, Amgen, AstraZeneca, Biotest, Bristol-Myers Squibb, Centocor, F Hoffmann-LaRoche, Genentech, Genzyme, Merck, Novartis, Nycomed, Pfizer, and UCB., Speakers bureau: AbbVie, Amgen, AstraZeneca, Biotest, Bristol-Myers Squibb, Centocor, F Hoffmann-LaRoche, Genentech, Genzyme, Merck, Novartis, Nycomed, Pfizer, and UCB. DOI: 10.1136/annrheumdis-2017-eular.2316

\section{THU0084 AGREEMENT BETWEEN THE DAS28-ESR AND THE DAS28-CRP AND FACTORS RELATED TO THE DISCREPANCIES BETWEEN DISEASE ACTIVITY LEVELS ACCORDING TO THESE 2 SCORES IN PATIENTS WITH EARLY RHEUMATOID ARTHRITIS: RESULTS FROM THE ESPOIR COHORT}

C. Gaujoux-Viala ${ }^{1,2}$, M. Belkacemi $^{3}$, A. Cantagrel ${ }^{4}$, B. Fautrel ${ }^{5}$, B. Combe ${ }^{6}$ ${ }^{1}$ Rheumatology, Nîmes University Hospital; ${ }^{2}$ EA2415, Montpellier University, Nîmes, ${ }^{3}$ IURC, EA2415, Montpellier: ${ }^{4}$ Rheumatology, Toulouse University
Hospital, Toulouse: ${ }^{5}$ Rheumatology, Pitié-Salpêtrière Hospital, APHP, Paris; ${ }^{6}$ Rheumatology, Lapeyronie Hospital, Montpellier, France

Background: DAS28 is often used as a treatment decision tool in patients with rheumatoid arthritis $(R A)$ in the daily clinic. Although different versions of DAS28 have previously been validated, and although disease activity thresholds are the same, it is not clear whether DAS28-ESR and DAS28-CRP can be used interchangeably in individual patients.

Objectives: The aims of our study were to examine the agreement between these two DAS28 versions in individual early RA patients in the daily clinic and to idenditify factors related to the discrepancies between disease activity levels according to these 2 scores.

Methods: Baseline and 6 months data from 677 patients with early RA (ACR EULAR 2010) were extracted from the French cohort of early arthritis ESPOIR (at least 2 swollen joints for less than 6 months, DMARD naïve) and were used to calculate DAS28-ESR and DAS28-CRP. Disease activity levels according to the DAS thresholds and EULAR responses were assessed. Intraclass correlation coefficient [ICC] and weighted kappa (k) were calculated. The Bland-Altman method was used to examine the bias between the DAS scores and the $95 \%$ limits of agreement (LoA). Multivariate logistic regression was used to determine the patient and RA features independently associated with discrepancies between disease activity levels according to DAS28-ESR and DAS28-CRP

Results: The mean value of DAS28-CRP $(5.04 \pm 1.16$ at M0 and $3.38 \pm 1.33$ at M6) was smaller than that of mean DAS28-ESR $(5.33 \pm 1.24$ at M0 and $3.51 \pm 1.42$ at M6). Agreement between the scores was excellent: ICC $=0.93$ at M0 and M6. Agreement between disease activity levels according to the 2 scores was good: $\mathrm{k}=0.70$ at $\mathrm{M0}$ and 0.75 at M6. Agreement between EULAR responses at M6 according to the 2 scores was good: $\mathrm{k}=0.78$. At M0, the bias of DAS28-CRP was -0.28 (LoA $-1.16,0.59$ ) and -0.14 (LoA -1.17, 0.89) at M6. There were discrepancies between disease activity levels according to the 2 scores in $122(18.6 \%)$ patients at M0 with clear difference in moderate (88 patients for DAS28-CRP vs 29 for DAS28-ESR) and high disease activity (18 patients for DAS28-CRP vs 80 for DAS28-ESR), and in 171 (28.1\%) patients at M6 with clear difference in remission (42 patients for DAS28-CRP vs 29 for DAS28-ESR) and high disease activity (9 patients for DAS28-CRP vs 32 for DAS28-ESR). At M0, presence of erosion (OR $95 \% \mathrm{Cl}=1.76[1.07-2.90]$ ), better mental component of the SF36 (OR 95\% Cl=2.14 [1.38-3.31]), fewer tender joint counts (TJC) and better physical component of the SF36 (PCS) (with significant interaction between TJC and PCS) were associated with discrepancies between disease activity levels according to the 2 scores. At M6, only being male (OR 95\% Cl=1.62 [1.09-2.41]) was associated with discrepancies.

Conclusions: DAS28-CRP significantly underestimated disease activity compared to DAS28-ESR. Agreement was high between the 2 scores, good for disease activity levels and EULAR responses. In the individual patient, however, the two scores may differ considerably. The scores should not be used interchangeably in the daily clinic without caution.

Disclosure of Interest: None declared

DOI: 10.1136/annrheumdis-2017-eular.6492

\section{THU0085 TIME TO REMISSION AND THE ACHIEVEMENT OF SUSTAINED REMISSION IN PATIENTS WITH EARLY RHEUMATOID ARTHRITIS: SITE VARIATION ANALYSIS IN THERAPEUTIC STRATEGY FROM THE CANADIAN EARLY ARTHRITIS COHORT (CATCH)}

C. Barnabe ${ }^{1}$, O. Schieir ${ }^{2}$, G. Hazlewood ${ }^{3}$, J. Pope ${ }^{4}$, C. Hitchon ${ }^{5}$, S. Bartlett ${ }^{6}$ G. Boire ${ }^{7}$, E. Keystone ${ }^{2}$, D. Tin ${ }^{8}$, B. Haraoui ${ }^{9}$, V. Bykerk ${ }^{10}$, C. Thorne ${ }^{8}$ on behalf of Canadian Early Arthritis Cohort (CATCH) Investigators. ${ }^{1}$ University of Calgary, Calgary; ${ }^{2}$ University of Toronto, Toronto; ${ }^{3}$ Medicine, University of Calgary, Calgary; ${ }^{4}$ Western University, London; ${ }^{5}$ University of Manitoba, Winnipeg; ${ }^{6}$ McGill University, Montreal; ${ }^{7}$ University of Sherbrooke, Sherbrooke; ${ }^{8}$ South lake Regional Health Centre, Newmarket; ${ }^{9}$ Universite de Montreal, Montreal, Canada; ${ }^{10}$ Hospital for Special Surgery, New York, United States

Background: Treatment response in ERA reflects individual prognostic factors and therapeutic selection which may be influenced by provider experience and beliefs. This may lead to variations in rates of and time to remission across centres involved in multi-site cohorts.

Objectives: We compared therapeutic strategies across Canadian ERA clinics in relation time to CDAl and DAS28 remission, and frequency of attaining sustained remission.

Methods: Data were analyzed for patients with $>1$ year of follow-up, enrolled at sites with $>40$ patients at baseline and $>30$ patients with 2 years of follow-up data. We determined time to remission and frequency of sustained remission (2 consecutive visits at least 6 months apart), using DAS28 and CDAI scores. Treatment strategy was determined as initial and ever use of oral methotrexate monotherapy, subcutaneous methotrexate monotherapy, methotrexate-based combinations, non-methotrexate DMARDs, triple therapy, or biologic therapy.

Results: 1,749 participants from 13 centers with mean age 54 years, $73 \%$ female, mean DAS28 4.9 (SD 1.4) and mean CDAI 25.6 (SD 14.6) were included. There were significant differences between centers in participant characteristics (gender, age, symptom duration, body mass index, comorbidities, smoking status, education, ethnicity, marital status, seropositive status, erosions). The 